\title{
About the activity and selectivity of less well-known metathesis catalysts during ADMET polymerizations
}

\author{
Hatice Mutlu ${ }^{1,2}$, Lucas Montero de Espinosa ${ }^{1,3}$, Oĝuz Türünç ${ }^{1,2}$ \\ and Michael A. R. Meier ${ }^{*} 1, \S$
}

\section{Full Research Paper}

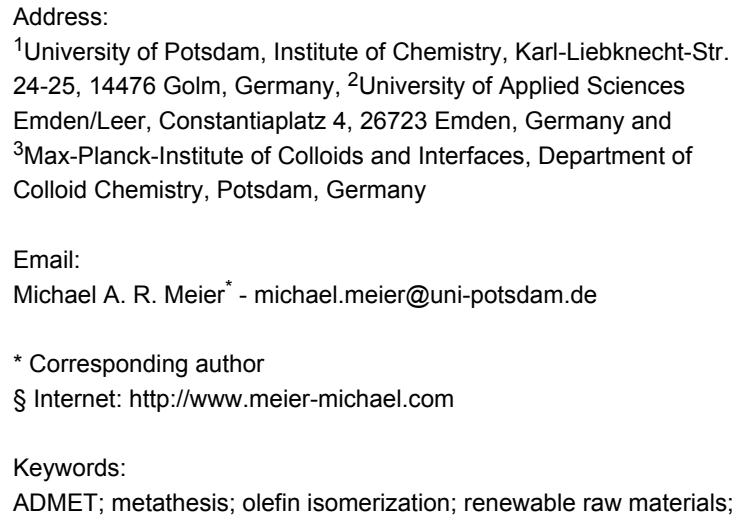

${ }^{1}$ University of Potsdam, Institute of Chemistry, Karl-Liebknecht-Str. 24-25, 14476 Golm, Germany, ${ }^{2}$ University of Applied Sciences Emden/Leer, Constantiaplatz 4, 26723 Emden, Germany and ${ }^{3}$ Max-Planck-Institute of Colloids and Interfaces, Department of Colloid Chemistry, Potsdam, Germany

Email:

Michael A. R. Meier ${ }^{*}$ - michael.meier@uni-potsdam.de

* Corresponding author

§ Internet: http://www.meier-michael.com

Keywords:

ADMET; metathesis; olefin isomerization; renewable raw materials;

ruthenium-indenylidene catalysts

\author{
Beilstein J. Org. Chem. 2010, 6, 1149-1158. \\ doi:10.3762/bjoc.6.131 \\ Received: 17 August 2010 \\ Accepted: 28 October 2010 \\ Published: 03 December 2010 \\ Guest Editor: K. Grela \\ (C) 2010 Mutlu et al; licensee Beilstein-Institut. \\ License and terms: see end of document.
}

\begin{abstract}
We report on the catalytic activity of commercially available Ru-indenylidene and "boomerang" complexes C1, C2 and C3 in acyclic diene metathesis (ADMET) polymerization of a fully renewable $\alpha, \omega$-diene. A high activity of these catalysts was observed for the synthesis of the desired renewable polyesters with molecular weights of up to $17000 \mathrm{Da}$, which is considerably higher than molecular weights obtained using the same monomer with previously studied catalysts. Moreover, olefin isomerization side reactions that occur during the ADMET polymerizations were studied in detail. The isomerization reactions were investigated by degradation of the prepared polyesters via transesterification with methanol, yielding diesters. These diesters, representing the repeat units of the polyesters, were then quantified by GC-MS.
\end{abstract}

\section{Introduction}

Among the large number of organic and organometallic reactions allowing the formation of carbon-carbon bonds, olefin metathesis has found its place in organic synthesis as well as polymer science as a very versatile tool that allows transformations that were previously not (or hardly) possible [1-6]. This academic and industrial success is also closely associated with the development and commercialization of efficient catalysts.
In the past few years, researchers realized that olefin isomerization is an important side reaction of Ru-catalyzed metathesis reactions. First reports on olefin isomerization claimed that this undesired side reaction was observed on substrates containing allylic oxygen or nitrogen functional groups in combination with first generation catalysts [7-11]. Later it was demonstrated that the degradation product of Grubbs $1^{\text {st }}$ generation catalyst 
was capable of catalyzing olefin isomerization [12]. Double bond isomerization was also observed with $2^{\text {nd }}$ generation catalysts on a broad variety of substrates competitively and sometimes prior to olefin metathesis [13-17]. In a number of other publications this problem was addressed and further discussions on the possible mechanism of the two proposed pathways, the $\pi$-allyl metal hydride and the metal hydride addition-elimination mechanisms, were reported [8,11,13-18]. In most cases isomerization was attributed to the presence of a Ru-hydride species $[13,14]$. The cause of formation of such Ru-hydride species was long a subject of discussion. Grubbs reported that certain ruthenium carbene complexes can thermally decompose to Ru-hydride species [19]. Moreover, mechanistic investigation of the thermal decomposition of the Grubbs second generation catalyst carried out by Grubbs and co-workers clearly showed that prolonged heating of the catalyst results in the formation of a binuclear ruthenium hydride complex [20]. The observation that this binuclear product was capable of efficiently isomerizing terminal olefins is a clear indication that metal hydride species are indeed the source of the isomerization. It was reported that a proper selection of solvents and additives can eliminate isomerization with $\mathrm{Ru}$-based metathesis catalysts in RCM [16]. The addition of $\mathrm{POCy}_{3}$ or oxygen inhibits isomerization, whereas the use of more coordinating solvents favors it. Additional research in this area reported that other types of additives, such as acetic acid [21], chlorocatecholborane [22], boron-based Lewis acid (such as: $\mathrm{Cy}_{2} \mathrm{BCl}$ ) [23], or $\mathrm{PhOP}(\mathrm{O})(\mathrm{OH})_{2}$ [24] can reduce the isomerization activity of the catalyst. Furthermore, Johnson and coworkers reported that during a RCM to make a 9-membered ring, chlorinated solvents, such as 1,2-dichloroethane, inhibited olefin isomerization [25]. Grubbs and collaborators showed that catalytic amounts $(10 \mathrm{~mol} \%)$ of 1,4-benzoquinone (BQ) can prevent the isomerization of a number of allylic ethers and long chain aliphatic alkenes during RCM and cross metathesis [21]. In the context of ADMET, isomerization of a terminal to an internal olefin, followed by a productive metathesis step with a terminal olefin, would liberate an $\alpha$-olefin, such as propene or 1-butene, as opposed to the ethylene liberated from a conventional ADMET reaction of two terminal olefins (Figure 1) [26]. Release of these higher condensate molecules would decrease the mass yield of the polymer, and if olefin isomerization occurs in a similar timescale as metathesis, this would result in polymers with ill-defined repeat units, which would also affect the physical properties of the polymer. Noteworthy, under ADMET conditions, the first-generation Ru-catalyst was found not to isomerize olefins [27].

In model studies carried out with simple olefins, Wagener and co-workers demonstrated that, while Grubbs $1^{\text {st }}$ generation and Schrock's molybdenum alkylidene catalysts did not produce

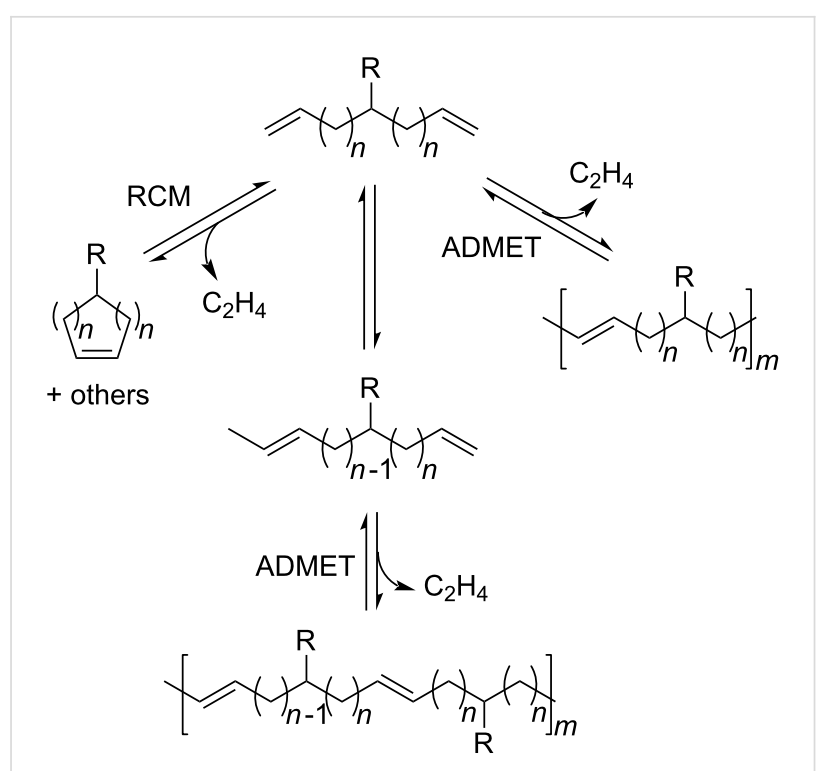

Figure 1: Olefin isomerization during ADMET polymerization.

appreciable double bond isomerization, Grubbs $2^{\text {nd }}$ generation catalyst presented significant isomerization activity, which was greatly reduced at temperatures below $30{ }^{\circ} \mathrm{C}[17,28]$. These studies were further complemented and confirmed by MALDI analysis of an amino acid polymer synthesized with Grubbs $2^{\text {nd }}$ generation catalyst [29].

Recently, a detailed study of temperature, catalyst, and polymerization condition dependent isomerization side reactions that occur during ADMET polymerizations was reported by Meier and Fokou [27]. The study clearly showed that high temperatures, such as $100^{\circ} \mathrm{C}$, increased the amount of isomerization for Grubbs $2^{\text {nd }}$ generation catalyst. In order to better understand the behavior of several second generation metathesis catalysts under ADMET conditions, their isomerization tendencies were subsequently studied [30]. The investigated catalysts showed high degrees of isomerization at $80^{\circ} \mathrm{C}$. The addition of BQ provided the best results in terms of reducing the isomerization reactions when added prior to the catalyst, indicating that catalyst decomposition begins as soon as the catalyst is added to the reaction mixture at high reaction temperatures. The effects of nitrogen purging and higher temperatures in the presence of BQ were also investigated and revealed that with nitrogen purging the degree of isomerization remained similar or even decreased.

Among the numerous metathesis initiators available, we focused this study on the application of the less investigated indenylidene Ru-based catalysts: (1,3-bis(2,4,6-trimethylphenyl)-2-imidazolidinylidene) dichloro-(3-phenyl-1H-inden-1ylidene)(tricyclohexylphosphine) ruthenium(II) (C1), (1,3- 
bis(2,4,6-trimethylphenyl)-2-imidazolidinylidene)dichloro-(3phenyl-1H-inden-1-ylidene)(pyridyl) ruthenium(II) (C2) and the newly developed "boomerang" complex $(1,3$-bis $(2,4,6$ trimethylphenyl)-2-imidazolidinylidene)dichloro(2-(1-methylacetoxy)phenyl)methylene ruthenium(II) (C3) [31] (Figure 2)

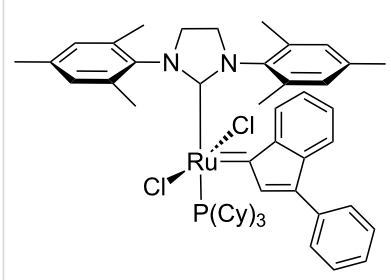

C1

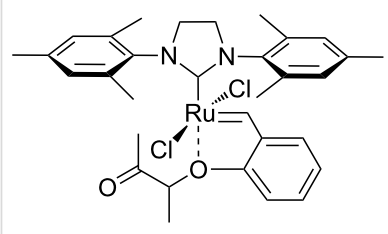

C3

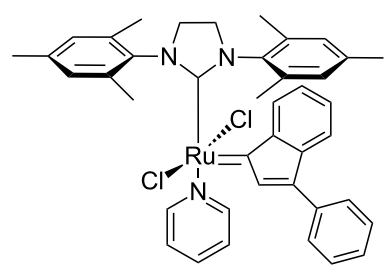

C2

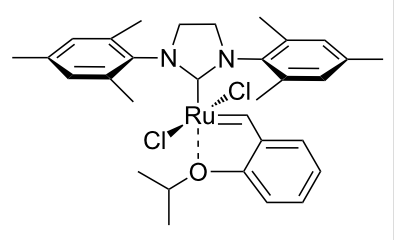

C4
Figure 2: Ru-indenylidene metathesis catalysts $\mathbf{C 1}$ and $\mathbf{C 2}$, "boomerang" complexes C3, and Hoveyda-Grubbs $2^{\text {nd }}$ generation catalyst C4 were studied for their efficiency and isomerization tendency in ADMET polymerizations.

These indenylidene $\mathrm{Ru}$-complexes provide an attractive alternative to the Ru-benzylidene compounds. It was shown that all indenylidene $\mathrm{Ru}$-catalysts were more robust under the demanding reaction conditions (temperature and functional group tolerance) compared to their $\mathrm{Ru}$-benzylidene counterparts [32-40]. In addition, good catalytic activities in RCM of linear dienes [32,34,35] and ROMP of cycloolefins [36-40] were reported. RCM studies with diethyl diallylmalonate and diallyl tosylamine as substrates showed an appreciable catalytic activity and selectivity for the $2^{\text {nd }}$ generation 16 -electron $\mathrm{Ru}$-indenylidene complex (C1) [41]. High temperatures allow for better ligand dissociation, and hence for a higher initiation rate of $\mathbf{C 1}$ in RCM [33,35]. Moreover, good activities were obtained in the self-metathesis reaction of undecylenic aldehyde, a renewable building block derived from castor oil cracking [42]. Research performed by Monsaert et al. illustrated that $\mathbf{C 2}$ enables high conversions in ROMP of 1,5cyclooctadiene, and conversions of up to $80 \%$ in the RCM of diethyl diallylmalonate in short reaction times (5-10 $\mathrm{min})$, thus being superior to the benzylidene analogue [35].

Recently, a useful and practical guide to application of olefin metathesis catalysts was published by Grela and co-workers [43]. They examined the effectiveness of $\mathrm{Ru}$-indenylidene complexes in standard olefin metathesis reactions and compared their activities to those of Grubbs and Hoveyda-Grubbs type catalysts. In contrast to Grubbs and Hoveyda-Grubbs catalysts, C1 was found to be practically inactive toward the RCM of diethyl diallymalonate at room temperature with catalyst loadings as low as $0.05 \mathrm{~mol} \%$. However, conversions dramatically increased when the reaction temperature was increased to 70 ${ }^{\circ} \mathrm{C}$. In addition, application of $\mathbf{C} \mathbf{1}$ to challenging substrates, such as diethyl di(methallyl)malonate in fluorinated aromatic hydrocarbon solvents, resulted in a remarkable enhancement of catalytic activity. Moreover, this approach was successfully extended to the RCM of natural products and the crossmetathesis formation of trisubstituted alkenes [44].

Thus, we decided to study the catalytic activity of C1, C2 and C3 in ADMET polymerizations. Furthermore, to gain insight into isomerization activities of the catalysts, detailed isomerization studies were also performed using a procedure already described in the literature [30]. The catalyst loading ( $0.5 \mathrm{~mol} \%)$ was kept constant throughout the entire screening process and temperatures varied from $60{ }^{\circ} \mathrm{C}$ to $120^{\circ} \mathrm{C}$ during the investigation.

\section{Results and Discussion}

To date, only one example of ADMET polymerization with an in situ generated $\mathrm{Ru}$-indenylidene catalyst has been reported [38]. The related arene $\mathrm{Ru}$-indenylidene complex (Figure 3) was generated in situ from $\left[\mathrm{RuCl}(p\right.$-cymene $)\left(=\mathrm{C}=\mathrm{C}=\mathrm{CPh}_{2}\right)$ $\left.\left(\mathrm{PCy}_{3}\right)\right]\left[\mathrm{CF}_{3} \mathrm{SO}_{3}\right]$, as the catalyst precursor and $\mathrm{HOSO}_{2} \mathrm{CF}_{3}$, and applied in the ADMET of 1,9-decadiene to yield a polymer with $94 \%$ conversion in $12 \mathrm{~h}$ at $0{ }^{\circ} \mathrm{C}$.

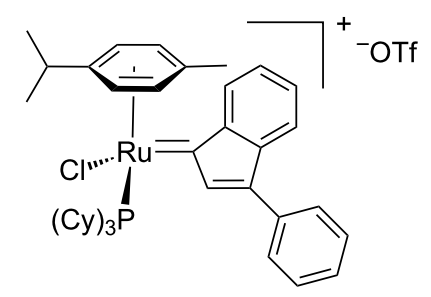

Figure 3: Representative scheme for the in situ generated Ru-indenylidene [38].

In this contribution, we report for the first time on the performance of two well-defined, stable $\mathrm{Ru}$-indenylidene catalysts $\mathbf{C 1}$ and C2, and the "boomerang complex" C3 (Figure 2) during ADMET polymerizations. The ADMET monomer was synthesized by a procedure adapted from the literature using 1,3propanediol, which can be prepared from glycerol, and 10-undecenoic acid [45], a commercial derivative of castor oil (Figure 4). A set of ADMET polymerizations was used to evaluate the performance of complexes C1, C2 and C3 at four 


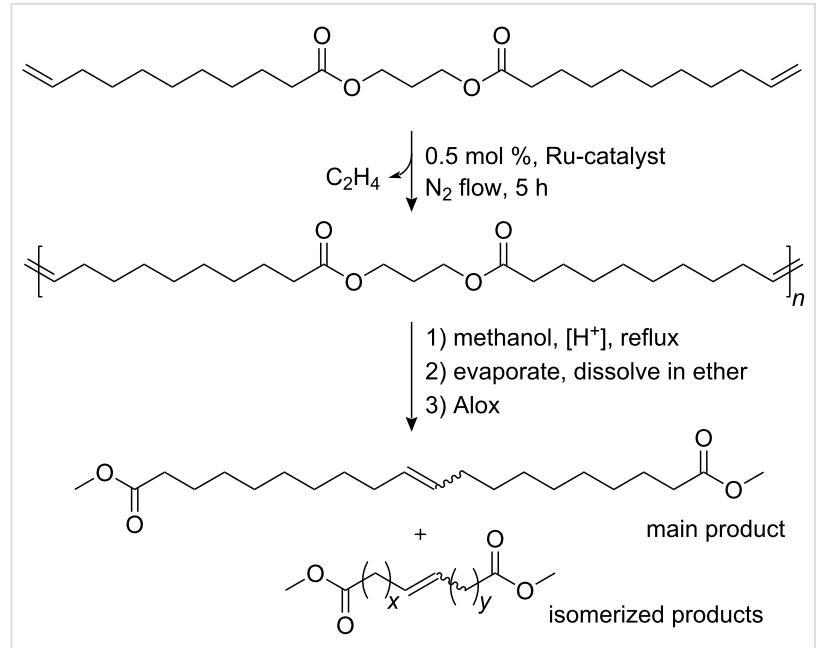

Figure 4: Synthesis of the studied $\alpha, \omega$-diene, its ADMET polymerization, and the strategy to evaluate isomerization side reactions.

different temperatures $\left(60,80,100\right.$ and $\left.120^{\circ} \mathrm{C}\right)$, under bulk conditions, after $5 \mathrm{~h}$ reaction time, and constant catalyst loading (200:1 = monomer 1 : catalyst). This provided a broad data set to screen the catalytic systems tested (Table 1 and Table 2). The activity of these catalysts was compared to the Hoveyda-Grubbs $2^{\text {nd }}$ generation catalyst $(\mathbf{C} 4)$, which was previously examined in ADMET polymerizations of the same monomer [30]. In all cases, continuous nitrogen purging was applied throughout the polymerizations and polymerizations were run in duplicate to obtain a reliable set of data.

Moreover, the resulting ADMET polymers were transesterified with methanol to yield $\alpha, \omega$-diesters, which were subsequently analyzed by GC-MS (Figure 4). For the polymerizations in which isomerization does not occur, the GC-MS would only show a single peak corresponding to the unsaturated C-20 repeating unit of the studied polymers (compare Figure 4). However, most ruthenium-based metathesis catalysts are known to promote olefin isomerization. As a result, the corresponding transesterified polymer yields a mixture of diesters with different chain lengths, since double bond isomerisation and olefin metathesis occur concurrently. The molecular weight of the isomerized diesters thus varies by multiples of $14 \mathrm{~g} / \mathrm{mol}$ (one methylene group).

The analytical data of the polymers synthesized is summarized in Table 1 and Table 2 and selected GPC traces are depicted in Figure 5. Except for the cases in which only oligomers were obtained, monomer conversion was quantitative as determined by the total disappearance of the monomer signal in the GPC traces of the reaction mixtures. The runs at $60{ }^{\circ} \mathrm{C}$ showed that, among C1, C2 and $\mathbf{C 3}$ (compare entries 1, 3 and 5 in Table 1, respectively; and Figure 4), C1 led to the highest molecular weight of around $10 \mathrm{kDa}$, with a moderate isomerization degree of $36.3 \%$ (Table 1, entry 1). Interestingly at this temperature, C2 showed a considerably lower degree of isomerization of 9.91\%; however only oligomers $\left(M_{\mathrm{n}} 1700 \mathrm{Da}\right)$ were obtained. Another goal of this research was to suppress the isomerization side reaction and thus to synthesize well-defined polyesters. Benzoquinones are very effective additives for the prevention of the olefin isomerization [21]. Thus, we performed the same set of experiments in the presence of $\mathbf{B Q}$, and observed that the degree of isomerization was significantly reduced for $\mathbf{C 1}$, from $36.3 \%$ to $0.7 \%$. However, this decrease in the degree of isomer-

\begin{tabular}{|c|c|c|c|c|c|c|c|}
\hline Entry & Polymer & $\begin{array}{l}\text { Cat \% } \\
{[0.5 \mathrm{~mol} \%]}\end{array}$ & Temp ${ }^{\circ} \mathrm{C}$ & Conditions $^{a}$ & Iso $\% b$ & $M_{\mathrm{n}}(\mathrm{Da})^{\mathrm{c}}$ & PDI \\
\hline 1 & P1 & C1 & 60 & & 36.3 & 10500 & 2.00 \\
\hline 2 & P2 & C1 & 60 & $\mathbf{B Q}[1 \%]$ & 0.70 & 8300 & 2.05 \\
\hline 3 & P3 & $\mathrm{C} 2$ & 60 & & 9.91 & 1700 & 1.16 \\
\hline 4 & P4 & $\mathrm{C} 2$ & 60 & $\mathbf{B Q}[1 \%]$ & $\mathrm{NI}^{\mathrm{d}}$ & 2200 & 1.36 \\
\hline 5 & P5 & $\mathrm{C} 3$ & 60 & & 69.6 & 8000 & 1.60 \\
\hline 6 & P6 & C3 & 60 & $\mathbf{B Q}[1 \%]$ & 63.9 & 4200 & 1.76 \\
\hline 7 & P7 & C1 & 80 & & 63.9 & 14000 & 1.92 \\
\hline 8 & P8 & C1 & 80 & $\mathbf{B Q}[1 \%]$ & 74.2 & 14000 & 2.09 \\
\hline 9 & P9 & $\mathrm{C} 2$ & 80 & & 41.9 & 14200 & 1.90 \\
\hline 10 & P10 & $\mathrm{C} 2$ & 80 & $\mathbf{B Q}[1 \%]$ & 28.6 & 9200 & 1.90 \\
\hline 11 & P11 & C3 & 80 & & 91.4 & 11850 & 1.80 \\
\hline 12 & P12 & $\mathrm{C} 3$ & 80 & $\mathbf{B Q}[1 \%]$ & 59.2 & 11300 & 1.93 \\
\hline
\end{tabular}

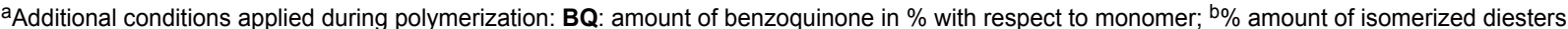
observed with GC-MS after transesterification of the respective polymer; ${ }^{\mathrm{C}} \mathrm{GPC}$ was performed in THF, containing BHT, with PMMA calibration; ${ }^{\mathrm{d}} \mathrm{NI}$ : no isomerization. 
Table 2: Overview of polymerization and the isomerization results of the corresponding polymers obtained at 100 and $120{ }^{\circ} \mathrm{C}$ after $5 \mathrm{~h}$ reaction time.

\begin{tabular}{|c|c|c|c|c|c|c|c|}
\hline Entry & Polymer & $\begin{array}{l}\text { Cat \% } \\
{[0.5 \mathrm{~mol} \%]}\end{array}$ & Temp ${ }^{\circ} \mathrm{C}$ & Conditions $^{a}$ & Iso $\% b$ & $M_{\mathrm{n}}(\mathrm{Da})^{\mathrm{c}}$ & PDI \\
\hline 13 & P13 & C1 & 100 & & 79.3 & 10000 & 1.79 \\
\hline 14 & P14 & C1 & 100 & $\mathbf{B Q}[1 \%]$ & 81.6 & 11300 & 1.74 \\
\hline 15 & P15 & $\mathrm{C} 2$ & 100 & & 53.6 & 9000 & 1.85 \\
\hline 16 & P16 & $\mathrm{C} 2$ & 100 & $\mathbf{B Q}[1 \%]$ & 0.80 & 4500 & 1.60 \\
\hline 17 & P17 & C3 & 100 & & 55.2 & 6700 & 1.72 \\
\hline 18 & P18 & C3 & 100 & BQ [1\%] & 37.2 & 10150 & 1.92 \\
\hline 19 & P19 & C1 & 120 & & 89.4 & 16700 & 1.80 \\
\hline 20 & P20 & C1 & 120 & BQ [1\%] & 73.0 & 11000 & 1.83 \\
\hline 21 & P21 & $\mathrm{C} 2$ & 120 & & 83.7 & 13000 & 1.66 \\
\hline 22 & P22 & $\mathrm{C} 2$ & 120 & BQ [1\%] & 16.0 & 8500 & 1.78 \\
\hline 23 & P23 & C3 & 120 & & 87.4 & 12200 & 1.73 \\
\hline 24 & P24 & C3 & 120 & $\mathbf{B Q}[1 \%]$ & 73.8 & 14850 & 1.73 \\
\hline 25 & P25 & C4 & 120 & & 80.5 & 10400 & 1.93 \\
\hline 26 & P26 & C4 & 120 & BQ [1\%] & 66.5 & 12000 & 1.67 \\
\hline
\end{tabular}

additional conditions applied during polymerization: BQ: amount of benzoquinone in \% respective to monomer; b\% amount of isomerized diesters observed with GC-MS after transesterification of the respective polymer ${ }^{\mathrm{C}} \mathrm{GPC}$ was performed in THF, containing BHT, with PMMA calibration..
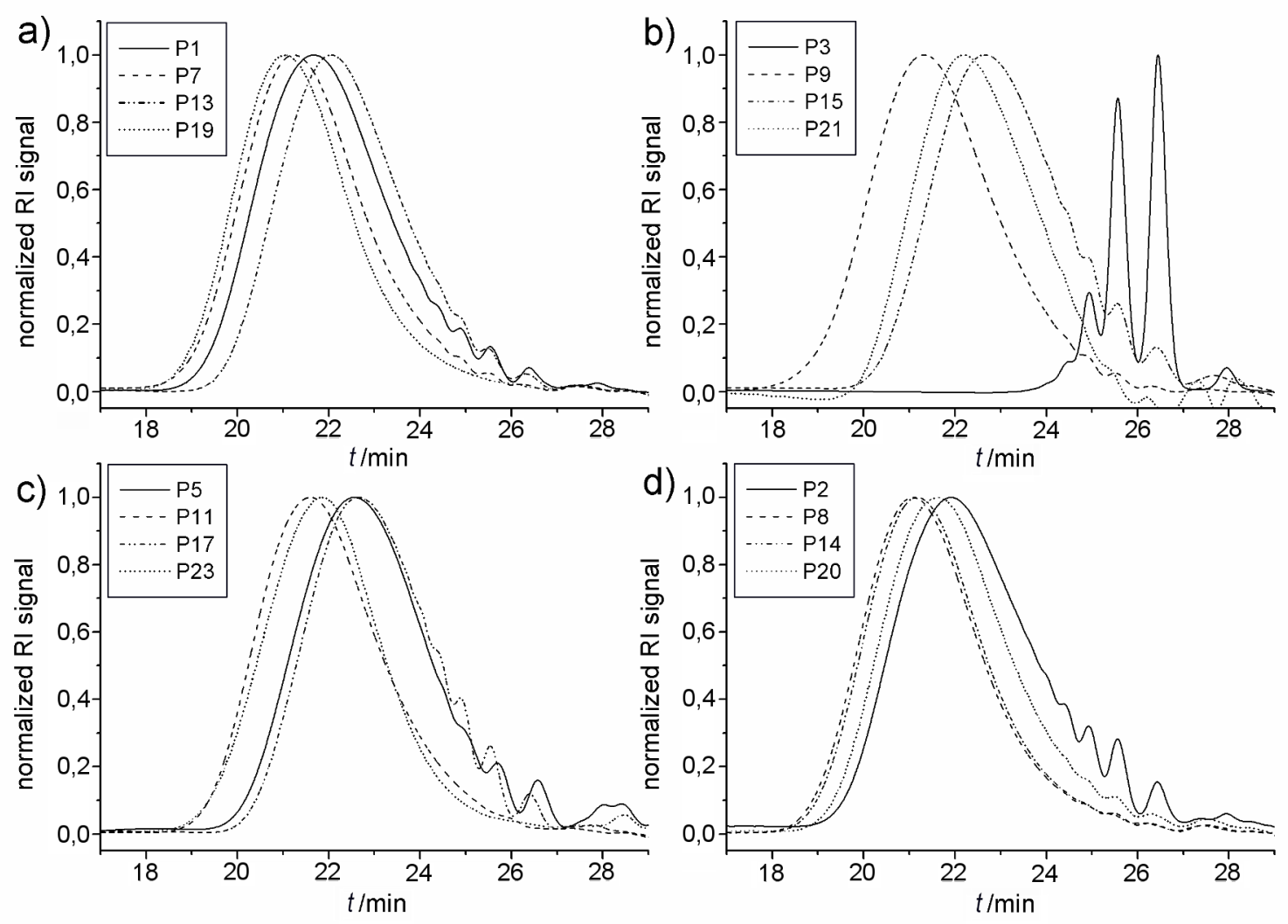

Figure 5: GPC traces of the polymerizations performed at $60,80,100$ and $120^{\circ} \mathrm{C}$ in presence of a) $0.5 \mathrm{~mol} \% \mathbf{C 1}$, b) $\left.0.5 \mathrm{~mol} \% \mathbf{C 2}, \mathrm{c}\right) 0.5 \mathrm{~mol} \% \mathbf{C 3}$, and d) $0.5 \mathrm{~mol} \%$ C1 with $1 \mathrm{~mol} \% \mathbf{B Q}$. 
ization was accompanied with reduced molecular weights for all studied catalysts. In the worst case of $\mathbf{C 2}$, the molecular weight was reduced by a factor of 3 (compare entries 3 and 4 in Table 1).

When the polymerization temperature was increased to $80{ }^{\circ} \mathrm{C}$, higher molecular weight polymers were obtained with all the studied catalysts. For instance, $\mathbf{C 2}$ produced a polymer with more than double the molecular weight when increasing the reaction temperature from 60 to $80{ }^{\circ} \mathrm{C}$. Furthermore, the increase of the temperature led to an increase in the amount of isomerization for all of the catalysts. Concerning the isomerization inhibition effect of $\mathbf{B Q}$ on the catalyst, the effect was significant (factor of 1.5) for $\mathbf{C 2}$ and $\mathbf{C 3}$, whereas BQ was ineffective in the presence of $\mathbf{C 1}$. In case of $\mathbf{C 3}$, the molecular weights of the corresponding polymers synthesized with and without BQ were similar, with a lower degree of isomerization for P12, as expected. Surprisingly, $\mathbf{C 1}$ showed a higher degree of isomerization in the presence of $\mathbf{B Q}$ at $80^{\circ} \mathrm{C}$.

In an attempt to further increase the molecular weights of the obtained polyesters, all catalysts were also investigated at 100 ${ }^{\circ} \mathrm{C}$ (Table 2). Surprisingly, this further increase of the polymerization temperature led to lower molecular weights for all the studied catalysts. Quite interestingly, at that temperature the most significant inhibition effect of $\mathbf{B Q}$ on the degree of isomerization was observed for C2 (compare entries 15 and 16 in Table 2), however, only oligomers were produced. Similarly as for the results at $80^{\circ} \mathrm{C}$, when we used $\mathbf{C 1}$ and $\mathbf{B Q}$, we observed an increase of the degree of isomerization along with similar $M_{\mathrm{n}}$ values (Table 2, entries 13 and 14). On the other hand, $\mathbf{C} 3$ showed the same tendency as at $80{ }^{\circ} \mathrm{C}$. The obtained polymers were less isomerized and had quite high molecular weights. The latter results with $\mathbf{C 3}$ are in good agreement with the results previously obtained for the structurally similar $\mathbf{C 4}$ [30].

Furthermore, the catalysts $\mathbf{C 1}, \mathbf{C 2}$, and $\mathbf{C 3}$, together with $\mathbf{C 4}$ for comparison, were investigated at $120^{\circ} \mathrm{C}$ (Table 2, entries 19 , 21,23 , and 25). All complexes provided comparatively high molecular weights, following the order $\mathbf{C 1}(\sim 17000 \mathrm{Da})>\mathbf{C 2}$ $(13000 \mathrm{Da})>\mathbf{C} 3(12200 \mathrm{Da})>\mathbf{C 4}(10500 \mathrm{Da})$. Regardless of the catalyst, all the polymers at that temperature possessed high isomerization values. Subsequently, we tried to reduce the amount of isomerization by performing the same set of reactions in the presence of $\mathbf{B Q}$ (Table 2, entries 20, 22, 24 and 26). The degree of isomerization was slightly reduced when using C1 (Figure 6a), and the most prominent effect of BQ was observed again for C2 (Figure 6b); however, this time the polymerization in the presence of $\mathbf{B Q}$ resulted in polymer with $M_{\mathrm{n}}$ of $8.5 \mathrm{kDa}$, compared to the results at lower temperatures. Inter- estingly, the polymerization with $\mathbf{C} \mathbf{3}$ in the presence of $\mathbf{B Q}$ followed the same tendency as at $100{ }^{\circ} \mathrm{C}$ and resulted in higher molecular weight polymers in comparison to the polymerization without BQ, whereas the isomerization remained high (Table 2, entries 23 and 24).
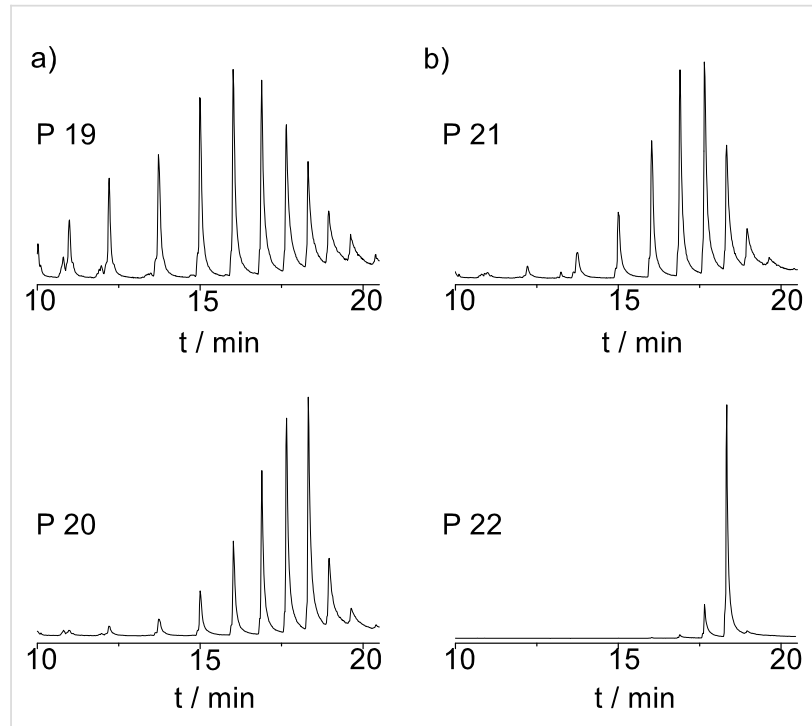

Figure 6: GC-MS study of the acid-catalyzed degradation products of polymers P19, P20, P21, and P22.

In a previous work, we reported that Hoveyda-Grubbs $2^{\text {nd }}$ generation catalyst $(\mathbf{C 4})$ yields polymers with molecular weights $M_{\mathrm{n}}$ of $8000 \mathrm{Da}$ at $80{ }^{\circ} \mathrm{C}$, and $8800 \mathrm{Da}$ at $100{ }^{\circ} \mathrm{C}$. The isomerization degrees were found to be $24 \%$ and $20 \%$, respectively [30]. Herein we have demonstrated that $\mathbf{C 4}$ can be used at a higher temperature $\left(120^{\circ} \mathrm{C}\right)$, in the presence of $\mathbf{B Q}$ ( $1 \mathrm{~mol} \%$ ), and with a low amount of catalyst $(0.5 \mathrm{~mol} \%)$, to yield a polymer with $M_{\mathrm{n}}$ of $12000 \mathrm{Da}$. However, at $120^{\circ} \mathrm{C}$ the amount of isomerization was high with and without $\mathbf{B Q}$ (entries 25 and 26, Table 2). These results, along with the results discussed in our previous work, clearly show that $\mathbf{C} \mathbf{4}$ can be used in a quite broad temperature range. Interestingly, BQ has a more pronounced effect in terms of isomerization inhibition, when compared to the structurally similar $\mathbf{C 3}$ over the whole temperature range studied.

In summary, the tendency found for the activity of these catalysts as a function of the temperature was not linear. A clear increase in the activities was observed on increasing the temperature from $60{ }^{\circ} \mathrm{C}$ to $80{ }^{\circ} \mathrm{C}$, however, when the temperature was increased to $100{ }^{\circ} \mathrm{C}$ a general activity decrease was observed for all the catalysts, and finally the activity increased again when performing the reactions at $120^{\circ} \mathrm{C}$. As the temperature is increased the activity of the catalyst increases, however, its degradation might also be accelerated. At $100{ }^{\circ} \mathrm{C}$, the deg- 
radation of the catalyst could be predominant, thus resulting in lower molecular weights. On the other hand, when the temperature is raised to $120^{\circ} \mathrm{C}$, the catalysts degradation could be compensated by an extremely fast initiation and short-term propagation promoted by the high temperature, giving as a result high molecular weight polymers before degradation of the catalysts occurs. This argumentation is speculative, but in order to provide some data to support this idea, the progress of the polymerization was examined at different times for $\mathbf{C} 1$ at 80 , 100 and $120^{\circ} \mathrm{C}$. Samples were taken at 5, 15, 30, and 120 minutes for each temperature and analyzed by GPC (Figure 7). As predicted from the arguments above, the propagation observed for the polymerization at $80{ }^{\circ} \mathrm{C}$ was slower than that at $100{ }^{\circ} \mathrm{C}$ at short times, however, the polymerization stalled at $100{ }^{\circ} \mathrm{C}$, possibly due to catalyst degradation, yielding lower molecular weights. Furthermore, the propagation in the initial steps for the polymerization at $120{ }^{\circ} \mathrm{C}$ was found to be the fastest, leading to high molecular weight species in short times before catalyst degradation became predominant.
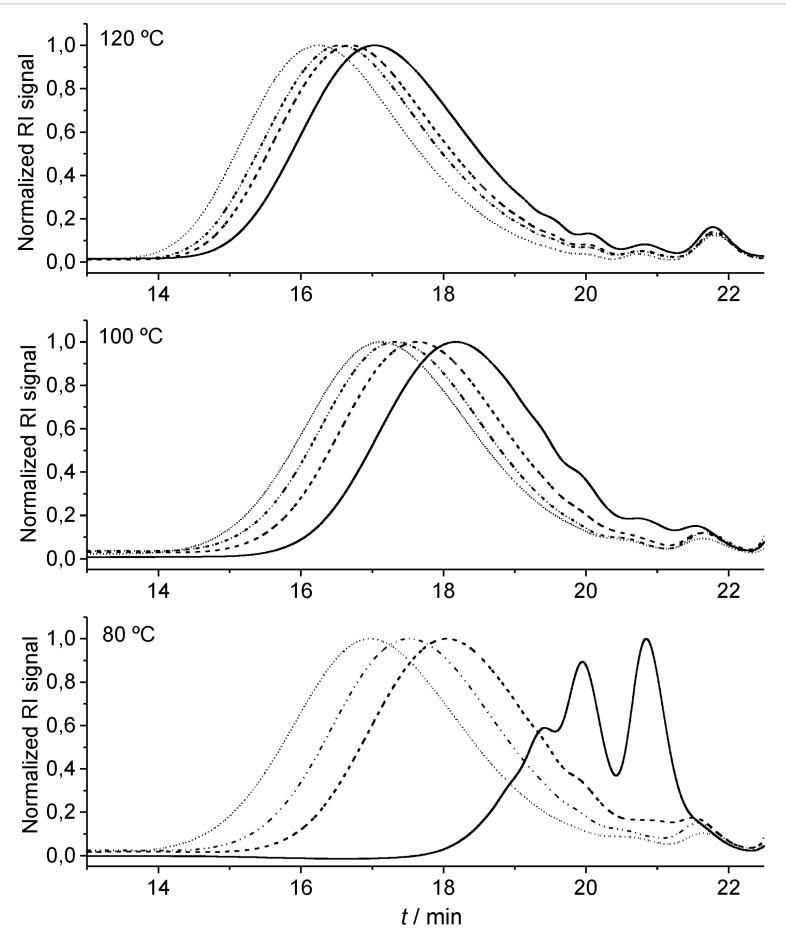

Figure 7: GPC traces of polymerizations performed with $\mathbf{C} 1$ at 80 , 100 , and $120^{\circ} \mathrm{C}$. Samples taken at $5 \mathrm{~min}(-), 15 \mathrm{~min}(-)$, $30 \mathrm{~min}(-\cdot)$, and $120 \mathrm{~min}(-)$.

Olefin isomerization occurring during ADMET polymerization leads to macromolecules with ill-defined structures. Depending on the degree of isomerization, the physical properties of the polymers are correspondingly affected. A different insight into the effect of the isomerization ratio on the thermal properties of the polymers can be achieved by differential scanning calori- metry (DSC) analysis of the synthesized polymers. The thermal behavior of two polymers with similar $M_{\mathrm{n}}$, synthesized at same temperature with and without BQ, was studied by DSC (Figure 8). Polymer P12 (Table 1, entry 12), possessing a lower degree of isomerization, exhibited a quite sharp $T_{\mathrm{m}}$ peak at 47 ${ }^{\circ} \mathrm{C}$. On the other hand, the DSC trace of polymer P11 (Table 1, entry 11), with higher isomerization degree, presented multiple peak melting transitions at lower temperatures resulting from its ill-defined repeat unit structure. These results show that, even if the addition of $\mathbf{B Q}$ does not completely avoid isomerization in most of the presented examples, polymers with a higher structural regularity can be obtained by with $\mathbf{B Q}$.

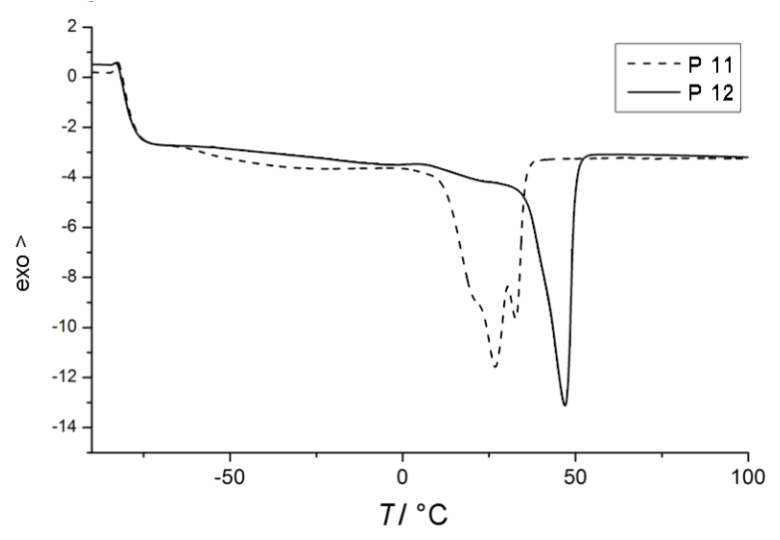

Figure 8: DSC traces of ADMET polymers P11 and P12 (Table 1, entries 11 and 12 , respectively).

\section{Conclusion}

The indenylidene Ru-complexes provided an attractive alternative to the benzylidene compounds and allowed polyesters of up to 17000 Da via ADMET polymerization to be prepared, even at elevated temperatures with enhanced activity. Unfortunately, the attempt to synthesize regular polymer architectures by the addition of $\mathbf{B Q}$ to supress the isomerization reaction, was rather unsuccessful. Nevertheless, the results presented should be regarded as a first experimental data set on these catalysts and further improvement, building on these results, can be expected in the future.

\section{Experimental Materials}

10-undecenoic acid (Sigma-Aldrich, 98\%), 1,3-propanediol (Sigma-Aldrich, 99.6\%), $p$-toluenesulfonic acid monohydrate (Sigma-Aldrich, 98.5\%), ethyl vinyl ether (Sigma-Aldrich, 99\%), sulfuric acid (Fluka, 95-97\%), $p$-benzoquinone (Fluka, 98\%), (1,3-bis(2,4,6-trimethylphenyl)-2-imidazolidinylidene) dichloro-(3-phenyl-1H-inden-1-ylidene)(tricyclohexylphosphine) ruthenium(II) (Umicore, C1), (1,3-bis(2,4,6-trimethyl- 
phenyl)-2-imidazolidinylidene)dichloro-(3-phenyl-1H-inden-1ylidene) (pyridyl) ruthenium(II) (Umicore, C2), (1,3-bis(2,4,6trimethylphenyl)-2-imidazolidinylidene)dichloro(2-(1-methylacetoxy)phenyl]methylene ruthenium(II) (Umicore, C3), (1,3bis(2,4,6-trimethylphenyl)-2-imidazolidinylidene)dichloro( $o$ isopropoxyphenylmethylene) ruthenium(II) (Hoveyda-Grubbs catalyst $2^{\text {nd }}$ generation, $\mathbf{C 4}$, Sigma-Aldrich).

\section{General Methods}

Thin layer chromatography (TLC) was performed on silica gel TLC-cards (layer thickness $0.20 \mathrm{~mm}$, Fluka). Compounds were visualized by permanganate reagent. For column chromatography silica gel $60(0.035-0.070 \mathrm{~mm}$, Fluka $)$ was used.

${ }^{1} \mathrm{H}$ NMR spectra were recorded in $\mathrm{CDCl}_{3}$ on Bruker AVANCE DPX spectrometers operating at 300 and $500 \mathrm{MHz}$. Chemical shifts $(\delta)$ are reported in parts per million relative to the internal standard tetramethylsilane (TMS, $\delta=0.00 \mathrm{ppm}$ ). For the analysis of the polymers the relaxation time was set to 5 seconds.

Mass spectra (ESI) were recorded on a VARIAN 500-MS ion trap mass spectrometer with the TurboDDS ${ }^{\mathrm{TM}}$ option installed. Samples were introduced by direct infusion with a syringe pump. Nitrogen served both as the nebulizer gas and the drying gas. Helium was used as cooling gas for the ion trap and collision gas for $\mathrm{MS}^{\mathrm{n}}$. Nitrogen was generated by a nitrogen generator Nitrox from Dominick Hunter.

GC-MS (EI) chromatograms were recorded with a Varian 431GC instrument with a capillary column FactorFourTM VF-5ms $(30 \mathrm{~m} \times 0.25 \mathrm{~mm} \times 0.25 \mu \mathrm{m})$ and a Varian 210-MS detector. Scans were performed from 40 to $650 \mathrm{~m} / \mathrm{z}$ at a rate of 1.0 scans $\times \mathrm{s}^{-1}$. The oven temperature was programmed as follows: initial temperature $95{ }^{\circ} \mathrm{C}$, hold for $1 \mathrm{~min}$, ramp at $15{ }^{\circ} \mathrm{C} \times \min ^{-1}$ to $200{ }^{\circ} \mathrm{C}$, hold for $2 \mathrm{~min}$, ramp at $15^{\circ} \mathrm{C} \times \min ^{-1}$ to $325^{\circ} \mathrm{C}$, hold for $5 \mathrm{~min}$. The injector transfer line temperature was set to 250 ${ }^{\circ} \mathrm{C}$. Measurements were performed in the split-split mode (split ratio 50:1) with helium as carrier gas (flow rate $1.0 \mathrm{ml} \times$ $\left.\min ^{-1}\right)$.

Polymer molecular weights were determined with an SEC System LC-20 A from Shimadzu equipped with a SIL-20A auto sampler, three PSS SDV columns $(5 \mu \mathrm{m}, 300 \mathrm{~mm} \times 7.5 \mathrm{~mm}$, $100 \AA, 1000 \AA, 10000 \AA$ ), and a RID-10A refractive index detector in THF (flow rate $1 \mathrm{~mL} \times \mathrm{min}^{-1}$ ) at $50{ }^{\circ} \mathrm{C}$. All determinations of molar mass were performed relative to PMMA standards (Polymer Standards Service, $M_{\mathrm{p}} 1100-981.000 \mathrm{Da}$ ).

Differential scanning calorimetry (DSC) experiments were carried out under a nitrogen atmosphere at a heating rate of $10^{\circ} \mathrm{C} \times \min ^{-1}$ with a DSC821e (Mettler Toledo) calorimeter up to a temperature of $150{ }^{\circ} \mathrm{C}$ with a sample mass of approximately $4 \mathrm{mg}$. The melting temperature, $T_{\mathrm{m}}$, was recorded as the peak of the endotherm on the second heating scan unless annealing was used as a pretreatment.

\section{Synthesis of 1,3-propylene diundec-10-enoate (1)}

10-Undecenoic acid (50.00 g, $0.27 \mathrm{~mol})$, 1,3-propanediol (8.4 g, $0.11 \mathrm{~mol})$ and $p$-toluensulfonic acid $(3 \mathrm{~g}, 0.0157 \mathrm{~mol})$ were placed in a round-bottomed flask provided with a magnetic stirrer and a Dean-Stark apparatus. Toluene $(200 \mathrm{~mL})$ was added and the resulting reaction mixture heated to reflux. Water was collected as the reaction proceeded and once the reaction was completed, the reaction mixture was allowed to cool. Toluene was removed under reduced pressure and the residue was filtered through a short pad of basic aluminium oxide with hexane as eluent. After removing the hexane, the crude product was dissolved in diethyl ether $(200 \mathrm{~mL})$ and washed two times with water $(200 \mathrm{~mL})$. The organic fraction was dried over anhydrous $\mathrm{MgSO}_{4}$ and the solvent removed under reduced pressure. The desired product was isolated in $87 \%$ yield $(39 \mathrm{~g})$.

${ }^{1} \mathrm{H}$ NMR $\left(\mathrm{CDCl}_{3}\right): \delta=5.85-5.76\left(\mathrm{~m}, 2 \mathrm{H}, 2 \mathrm{x}-\mathrm{CH}=\mathrm{CH}_{2}\right)$, $5.00-4.91\left(\mathrm{~m}, 4 \mathrm{H}, 2 \times \mathrm{CH}=\mathrm{CH}_{2}\right), 4.15(\mathrm{t}, 4 \mathrm{H}, \mathrm{J}=6.1 \mathrm{~Hz}$, $\left.2 \mathrm{xCH} \mathrm{H}_{2} \mathrm{OCO}-\right), 2.30$ (t, $\left.4 \mathrm{H}, J=7.3 \mathrm{~Hz}, \mathrm{CH}_{2} \mathrm{COO}-\right), 2.00$ (m, 4H, $\left.2 \mathrm{xCH}_{2}-\mathrm{CH}=\mathrm{CH} 2\right), 1.99-1.94(\mathrm{~m}, 2 \mathrm{H}, J=6.1 \mathrm{~Hz}$, $\left.\mathrm{CH}_{2} \mathrm{CH}_{2} \mathrm{OCO}-\right), 1.64-1.58\left(\mathrm{~m}, 4 \mathrm{H}, 2 \mathrm{xCH}_{2} \mathrm{CH}_{2} \mathrm{COO}-\right)$, 1.38-1.34 (m, 4H, 2xCH 2 ) 1.29-1.24 (br.s, 16H, 2x[4CH $\left.\mathrm{CH}_{2}\right]$ ppm. ${ }^{13} \mathrm{C}$ NMR (CDC13): $\delta=173.6$ (s, -COO-), 139.0 (s, $\left.-\mathrm{CH}=\mathrm{CH}_{2}\right), 114.1$ (s, $\left.-\mathrm{CH}=\mathrm{CH}_{2}\right), 60.7$ (s, $\left.\mathrm{CH}_{2} \mathrm{OCO}-\right), 34.1$ (s, $\mathrm{CH}_{2}$ ), 33.7 (s, $\mathrm{CH}_{2}$ ), 29.2 (s, $\mathrm{CH}_{2}$ ), 29.1 (s, $\mathrm{CH}_{2}$ ), 29.0 (s, $\mathrm{CH}_{2}$ ), $28.8\left(\mathrm{~s}, \mathrm{CH}_{2}\right), 24.8\left(\mathrm{~s}, \mathrm{CH}_{2}\right)$ ppm. MS (EI): $m / z=408[\mathrm{M}]^{+}$, calc. 408.3239 .

\section{ADMET polymerization (P1-P26)}

To $1 \mathrm{~g}$ (2.45 mmol) of 1,3-propylene diundec-10-enoate in a tube equipped with a screw, $0.5 \mathrm{~mol} \%$ of the corresponding ruthenium catalyst, (C1: $11.6 \mathrm{mg}(0.0122 \mathrm{mmol}), \mathbf{C 2}: 9.1 \mathrm{mg}$ (0.0122 mmol), C3: $8 \mathrm{mg}(0.0122 \mathrm{mmol})$ and $\mathbf{C 4}: 7.7 \mathrm{mg})$ was added at the desired reaction temperature $\left(60-120^{\circ} \mathrm{C}\right)$. In some cases, $1 \mathrm{~mol} \%$ of $\mathbf{B Q}$ was added to the reaction mixture $10 \mathrm{~min}$ before the addition of the catalyst. Reactions were carried out in parallel using a carousel reaction station from Radleys. Stirring was continued at the selected temperature under a continuous flow of nitrogen for $5 \mathrm{~h}$. After $5 \mathrm{~h}$ reaction time, the reaction mixture was dissolved in $1 \mathrm{~mL}$ of THF and polymerization halted by the addition of $1 \mathrm{~mL}$ of ethyl vinyl ether. The mixture was then stirred for $30 \mathrm{~min}$ at room temperature. The crude product was purified by precipitation into cold methanol. Final polymer molecular weights were determined after precipitation with the above mentioned GPC system. 


\section{Transesterification of the obtained polymers (P1-} P26) and GC-MS analysis

The respective polymer $(30 \mathrm{mg})$, excess methanol $(4 \mathrm{~mL})$ and concentrated sulfuric acid ( 5 drops) were added to a carousel reaction tube, stirred magnetically, and refluxed at $85^{\circ} \mathrm{C}$ for 5 $h$. At the end of the reaction, the excess of methanol was removed under reduced pressure. The residue was then dissolved in diethyl ether and filtered through a small column of basic aluminium oxide. Subsequently, GC-MS samples were prepared by taking $500 \mu \mathrm{L}$ of this solution and diluting it with methanol $(500 \mu \mathrm{L})$. The percentage of olefin isomerization was calculated based on peak areas of the isomerized diesters.

\section{Acknowledgements}

This work was partially financially supported by the German Federal Ministry of Food, Agriculture and Consumer Protection (represented by the Fachagentur Nachwachsende Rohstoffe). LME is grateful for a Max Planck postdoctoral fellowship. The authors are grateful to Prof. Beuermann for providing access to DSC equipment and to Umicore for their generous donation of catalysts.

\section{References}

1. Schuster, M.; Blechert, S. Angew. Chem., Int. Ed. 1997, 36, 2036-2056. doi:10.1002/anie.199720361

2. Fürstner, A. Angew. Chem., Int. Ed. 2000, 39, 3012-3043. doi:10.1002/1521-3773(20000901)39:17<3012::AID-ANIE3012>3.0.CO ;2-G

3. Trnka, T. M.; Grubbs, R. H. Acc. Chem. Res. 2001, 34, 18-29. doi:10.1021/ar000114f

4. Connon, S.; Blechert, S. Angew. Chem. 2003, 115, 1944-1968. doi:10.1002/ange.200200556

5. Grubbs, R. H. Tetrahedron 2004, 60, 7117-7140. doi:10.1016/j.tet.2004.05.124

6. Rybak, A.; Fokou, P. A.; Meier, M. A. R. Eur. J. Lipid Sci. Technol. 2008, 110, 797-804. doi:10.1002/ejlt.200800027

7. Miller, S. J.; Blackwell, H. E.; Grubbs, R. H. J. Am. Chem. Soc. 1996, 118, 9606-9614. doi:10.1021/ja961626l

8. Maynard, H. D.; Grubbs, R. H. Tetrahedron Lett. 1999, 40, 4137-4140. doi:10.1016/S0040-4039(99)00726-1

9. Bourgeois, D.; Pancrazi, A.; Ricard, L.; Prunet, J. Angew. Chem., Int. Ed. 2000, 112, 742-744. doi:10.1002/(SICI)1521-3773(20000218)39:4<725::AID-ANIE725>3.0. CO;2-I

10. Edwards, S. D.; Lewis, T.; Taylor, R. J. K. Tetrahedron Lett. 1999, 40, 4267-4270. doi:10.1016/S0040-4039(99)00703-0

11. Schmidt, B.; Wildemann, H. J. Org. Chem. 2000, 65, 5817-5822. doi:10.1021/jo005534x

12. Dinger, M. B.; Mol, J. C. Adv. Synth. Catal. 2002, 344, 671-677. doi:10.1002/1615-4169(200208)344:6/7<671::AID-ADSC671>3.0.CO;2 $-G$

13. Fürstner, A.; Thiel, O. R.; Ackermann, L.; Schanz, H.-J.; Nolan, S. P. J. Org. Chem. 2000, 65, 2204-2207. doi:10.1021/jo9918504

14. Sutton, A. E.; Seigal, B. A.; Finnegan, D. F.; Snapper, M. L. J. Am. Chem. Soc. 2002, 124, 13390-13391. doi:10.1021/ja028044q
15. Sworen, J. C.; Pawlow, J. H.; Case, W.; Lever, J.; Wagener, K. B. J. Mol. Catal. 2002, 194, 69-78. doi:10.1016/S1381-1169(02)00524-1

16. Bourgeois, D.; Pancrazi, A.; Nolan, S. P.; Prunet, J.

J. Organomet. Chem. 2002, 643, 247-252.

doi:10.1016/S0022-328X(01)01269-4

17. Lehman, S. E., Jr.; Schwendeman, J. E.; O'Donnell, P. M.; Wagener, K. B. Inorg. Chim. Acta 2002, 345, 190-198. doi:10.1016/S0020-1693(02)01307-5

18. Schmidt, B. Eur. J. Org. Chem. 2004, 1865-1880. doi:10.1002/ejoc.200300714

19. Louie, J.; Grubbs, R. H. Organometallics 2002, 21, 2153-2164. doi:10.1021/om011037a

20. Hong, S. H.; Day, M. W.; Grubbs, R. H. J. Am. Chem. Soc. 2004, 126, 7414-7415. doi:10.1021/ja0488380

21. Hong, S. H.; Sanders, D. P.; Lee, C. W.; Grubbs, R. H. J. Am. Chem. Soc. 2005, 127, 17160-17161. doi:10.1021/ja052939w

22. Moïse, J.; Arseniyadis, S.; Cossy, J. Org. Lett. 2007, 9, 1695-1698. doi:10.1021/ol0703940

23. Vedrenne, E.; Dupont, H.; Oualef, S.; Elkaïm, L.; Grimaud, L. Synlett 2005, 4, 670-672. doi:10.1055/s-2005-862375

24. Formentin, P.; Gimeno, N.; Steinke, J. H. G.; Vilar, R. J. Org. Chem. 2005, 70, 8235-8238. doi:10.1021/jo051120y

25. Campbell, J. M.; Johnson, S. J. Am. Chem. Soc. 2009, 131, 10370-10371. doi:10.1021/ja904136q

26. Mutlu, H.; Montero de Espinosa, L.; Meier, M. A. R. Chem. Soc. Rev. 2011, in press. doi:10.1039/b924852h

27. Fokou, P. A.; Meier, M. A. R. J. Am. Chem. Soc. 2009, 131, 1664-1665. doi:10.1021/ja808679w

28. Courchay, F. C.; Sworen, J. C.; Wagener, K. B. Macromolecules 2003, 36, 8231-8239. doi:10.1021/ma0302964

29. Petkovska, V. I.; Hopkins, T. E.; Powell, D. H.; Wagener, K. B. Macromolecules 2005, 38, 5878-5885. doi:10.1021/ma050480k

30. Fokou, P. A.; Meier, M. A. R. Macromol. Rapid Commun. 2010, 31, 368-373. doi:10.1002/marc.200900678

31. Arlt, D.; Bieniek, M.; Karch, R. Novel Metathesis Catalysts. PCT/EP2007/007972, Sept 13, 2007

32. Jafarpour, L.; Schanz, H.-J.; Stevens, E. D.; Nolan, S. P. Organometallics 1999, 18, 5416-5419. doi:10.1021/om990587u

33. Broggi, J.; Urbina-Blanco, C. A.; Clavier, H.; Leitgeb, A.; Slugovc, C.; Slawin, A. M. Z.; Nolan, S. P. Chem.-Eur. J. 2010, 16, 9215-9225. doi:10.1002/chem.201000659

34. Clavier, H.; Petersen, J. L.; Nolan, S. P. J. Organomet. Chem. 2006, 691, 5444-5447. doi:10.1016/j.jorganchem.2006.08.007

35. Monsaert, S.; Drozdzak, R.; Dragutan, V.; Dragutan, I.; Verpoort, F. Eur. J. Inorg. Chem. 2008, 432-440. doi:10.1002/ejic.200700879

36. de Fremont, P.; Clavier, H.; Montembault, V.; Fontaine, L.; Nolan, S. P. J. Mol. Catal. A: Chem. 2008, 283, 108-113. doi:10.1016/j.molcata.2007.11.038

37. Opstal, T.; Verpoort, F. Angew. Chem., Int. Ed. 2003, 42, 2876-2879. doi:10.1002/anie.200250840

38. Castarlenas, P.; Dixneuf, P. H. Angew. Chem., Int. Ed. 2003, 42, 4524-4527. doi:10.1002/anie.200352108

39. Adekunle, O.; Tanner, S.; Binder, W. H. Beilstein J. Org. Chem. 2010, 6, No. 59. doi:10.3762/bjoc.6.59

40. Burtscher, D.; Lexer, C.; Mereiter, K.; Winde, R.; Karch, R.; Slugovc, C. J. Polym. Sci., Part A: Polym. Chem. 2008, 46, 4630-4635. doi:10.1002/pola.22763

41. Clavier, H.; Nolan, S. P. Chem.-Eur. J. 2007, 13, 8029-8036. doi:10.1002/chem.200700256 
42. Miao, X.; Fischmeister, C.; Bruneau, C.; Dixneuf, P. H. ChemSusChem 2009, 2, 542-545. doi:10.1002/cssc.200900028

43. Bieniek, M.; Michrowska, A.; Usanov, D. L.; Grela, K. Chem.-Eur. J. 2008, 14, 806-818. doi:10.1002/chem.200701340

44. Samojlowicz, C.; Bieniek, M.; Zarecki, A.; Kadyrov, R.; Grela, K. Chem. Commun. 2008, 6282-6284. doi:10.1039/b816567j

45. Mutlu, H.; Meier, M. A. R. Eur. J. Lipid Sci. Technol. 2010, 112, 10-30. doi:10.1002/ejlt.200900138

\section{License and Terms}

This is an Open Access article under the terms of the Creative Commons Attribution License

(http://creativecommons.org/licenses/by/2.0), which permits unrestricted use, distribution, and reproduction in any medium, provided the original work is properly cited.

The license is subject to the Beilstein Journal of Organic Chemistry terms and conditions:

(http://www.beilstein-journals.org/bjoc)

The definitive version of this article is the electronic one which can be found at: doi:10.3762/bjoc. 6.131 